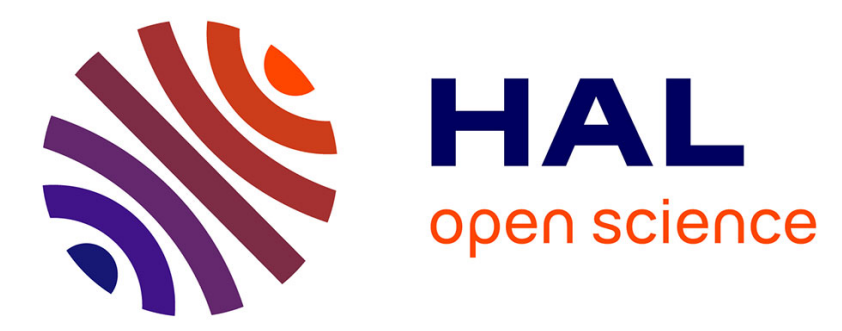

\title{
Designing III-V multijunction solar cells on silicon
}

James P. Connolly, Denis Mencaraglia, Charles Renard, Daniel Bouchier

\section{To cite this version:}

James P. Connolly, Denis Mencaraglia, Charles Renard, Daniel Bouchier. Designing III-V multijunction solar cells on silicon. Progress in Photovoltaics, 2014, 22 (7), pp.810-820. 10.1002/pip.2463 . hal-01099347

\section{HAL Id: hal-01099347 \\ https://hal-centralesupelec.archives-ouvertes.fr/hal-01099347}

Submitted on 3 Aug 2020

HAL is a multi-disciplinary open access archive for the deposit and dissemination of scientific research documents, whether they are published or not. The documents may come from teaching and research institutions in France or abroad, or from public or private research centers.
L'archive ouverte pluridisciplinaire $\mathbf{H A L}$, est destinée au dépôt et à la diffusion de documents scientifiques de niveau recherche, publiés ou non, émanant des établissements d'enseignement et de recherche français ou étrangers, des laboratoires publics ou privés. 
PAPER PRESENTED AT 28TH EU PVSEC, PARIS, FRANCE, 2013

\title{
Q1 Designing III-V multijunction solar cells on silicon
}

\author{
James P. Connolly ${ }^{1}{ }^{*}$, Denis Mencaraglia ${ }^{2}$, Charles Renard ${ }^{3}$ and Daniel Bouchier ${ }^{3}$ \\ Q2 ${ }^{1}$ Nanophotonics Technology Center, Universidad Politécnica de Valencia, B 8F, 2². Camino de Vera s/n. 46022, Valencia, Spain \\ 2 LGEP, UMR CNRS 8507, Supelec, Université Pierre et Marie Curie, Université Paris-sud, 11 rue Joliot-Curie, 91192 Gif-sur-Yvette, France \\ 3 IEF, UMR CNRS 8622, Université Paris-Sud, Orsay F-91405, France
}

\section{ABSTRACT}

Single junction Si solar cells dominate photovoltaics but are close to their efficiency limits. This paper presents ideal limiting efficiencies for tandem and triple junction multijunction solar cells featuring a Si subcell also serving as substrate. Subject to this Si bandgap constraint, we design optimum cell structures that we show depart from the unconstrained ideal. In order to progress to manufacturable designs, the use of III-V materials is considered, using a novel growth method capable of yielding low defect density III-V layers on Si. In order to evaluate the real potential of these proposed multijunction designs, a quantitative model is presented, the strength of which is the joint modelling of external quantum efficiency and current-voltage characteristics using the same parameters. The method yields a single-parameter fit in terms of the Shockley-Read-Hall lifetime. This model is validated by fitting experimental data of external quantum efficiency, dark current and conversion efficiency of world record tandem and triple junction cells under terrestrial solar spectra without concentration. We apply this quantitative model to the design of tandem and triple junction solar cells, yielding cell designs capable of reaching efficiencies without concentration of $32 \%$ for the best tandem cell and $36 \%$ for the best triple junction cell. This demonstrates that efficiencies within a few per cent of world records are realistically achievable without the use of concentrating optics, with growth methods being developed for multijunction cells combining III-V and Si materials. Copyright (C) 2013 John Wiley \& Sons, Ltd.

KEYWORDS

modelling; multijunction; silicon; III-V; terrestrial; high efficiency

* Correspondence

James P. Connolly, Nanophotonics Technology Center, Universidad Politécnica de Valencia, B 8F, $2^{\circ}$. Camino de Vera s/n. 46022, Valencia, Spain

E-mail: connolly@ntc.upv.es

Received 28 June 2013; Revised 20 September 2013; Accepted 4 December 2013

\section{INTRODUCTION}

Multijunction cells remain the most successful high efficiency design concept and the only one successfully commercialised. Nevertheless, these structures are still restricted to niche applications in space and under concentration, although generic terrestrial applications are tantalisingly close. The materials most suitable for multijunction designs are the III-V materials families, given their range of optical and material properties where incompatibilities, especially due to lattice constants, may be managed or even eliminated. The classic example is the growth of GaInP and GaInAs top and middle gap junctions on Ge substrates as bottom cell. This triple junction has achieved efficiencies [1] under concentration greater than $40 \%$ with both lattice-matched and lattice-mismatched approaches.

The main obstacles to the widespread use of multijunctions in renewable energy supply are materials and fabrication issues. The materials cost is partly due to the scarcity of some essential III-V materials such as In and Ga, but more importantly, it is due to the use of expensive substrates, because even Ge remains relatively costly in the competitive photovoltaic market.

Concerning cheap substrates, the clear front-runner is $\mathrm{Si}$, which brings with it the advantage of low-cost industry-standard CMOS processing technologies and more Q4 specifically brings the advantage of the most advanced development for commercial solar cells. The additional need for III-V materials is barely a few microns, reducing the materials cost to acceptable levels.

However, Si suffers from a lack of semiconductors lattice matched to it and from an indirect bandgap and low absorption coefficient. This is an obstacle for most optoelectronic applications including multijunction solar cell design. Although all-Si structures have been proposed, using amorphous silicon and silicon-based metamaterials to fabricate multijunction 
cells [2], the most attractive and most flexible option remains growth of high quality III-V materials on $\mathrm{Si}$.

An early attempt to address this issue by Yang [3] simply grew a thick AlGaAs buffer layer on an active Si substrate, with a simple three-terminal design. This approach did not exceed efficiencies of $20 \%$ and has not to date been developed further. Some years later, Taguchi et al. [4] adopted a not dissimilar structure with a high quality GaAs cell grown on a GaAs substrate and transferred to a Si substrate by liftoff. They chose a four-terminal design but again failed to demonstrate more than $19 \%$ efficiency.

Geisz et al. have since reported results on two-terminal designs. They have investigated both lattice-matched attempts using nitrides [5] and lattice-mismatched approaches using graded buffer techniques for strain relaxation minimising bulk defect densities [6]. The work of Lueck et al. [7] in the same year demonstrated similar techniques and achieved an efficiency of $17 \%$ under AM1.5G spectrum. Work in this field continues with Putyato et al. [8] developing graded buffer approaches. While these methods have made progress, the efficiencies achieved remain subject to materials quality limitations due to the fundamental problem of high defect densities, despite the use of buffers to reduce them to acceptable levels.

This paper presents a quantitative study of silicon-based multijunction solar cells for terrestrial applications developed by the Multispectral Solar Cells on Silicon (MULTISOLSI) project [9]. The study assumes an AM1.5G spectrum that corresponds to photovoltaic systems with no solar concentration. This is suitable for strategies prioritising a low system cost over cell efficiency and peak power. However, we are also aiming at relatively low cell cost with our silicon-based design, while nevertheless reaching high efficiencies. While a detailed cost analysis on this point is beyond the scope of this paper, we note that the cell design methodology we describe is equally applicable to concentrating photovoltaics under direct solar spectra. The choice of a global spectrum does not, therefore, limit the scope of the design methods we will describe.

A detailed growth investigation presented in a companion paper [10] reports on progress in the development of III-V growth on Si using novel low-cost three-dimensional growth techniques within this project. This technique involves epitaxial lateral overgrowth of lattice-mismatched polar semiconductors on $\mathrm{Si}$ via growth of nano-seeds in apertures opened in thin $\mathrm{SiO}_{2}$ layers. This technique has demonstrated defect-free growth and an absence of antiphase domain formation [11] due to the small initial growth area. This paper therefore does not consider the formidable materials issues that remain to be resolved within MULTISOLSI but concentrates on the design stage only by evaluating the potential of III-V structures on Si using a validated, quantitative model.

We first examine the suitability of silicon for multijunction cells from the commonly used ideal theoretical viewpoint of the radiative limit but amended to maximise the radiative efficiency of multijunction cells with nonideal bandgaps and layer thicknesses. We then describe a quantitative analytical model capable of accurately modelling record multijunction cells. On this basis, we present the design basis for dual and triple junction cells being currently developed in the MULTISOLSI project.

\section{IDEAL EFFICIENCY LIMITS}

With the objective of this study being cheap terrestrial Q5 multijunction photovoltaic systems, it is instructive to first look at the suitability of $\mathrm{Si}$ in the ideal limit under the AM1.5G spectrum that we perform by looking at the maximum efficiencies achievable using silicon in multijunction cells in the radiative efficiency limit, using the form published by Henry [12]. The ideal system considered consists of a stack of $N$ subcells of index $i$, each of unit external quantum efficiency (EQE), and converts every photon absorbed into a current carrier. Each subcell of bandgap $E_{g i}$ absorbs light in the wavelength range corresponding to energies between $E_{g i}$, and $E_{g i+1}$ with obvious modifications for the first and Nth cells. For this system, under spectral irradiance $F$, and adopting the photovoltaic sign convention of positive photocurrent, the short circuit current density $J_{S C i}$ and the radiative saturation current density $J_{0 i}$ of each subcell take the form

$$
\begin{gathered}
J_{S C_{i}}=q \int_{E_{g_{i}}}^{E_{g_{i}+1}} F(\lambda) \frac{\lambda}{h c} d \lambda \\
J_{0 i}=\frac{q\left(n_{i}^{2}+1\right) E_{g i}^{2} K_{B} T}{4 \pi^{2} c^{2}} e\left(\frac{-E_{g i}}{K_{B} T}\right)
\end{gathered}
$$

where $n_{i}$ is the subcell refractive index (taken as 3.5 here as in Henry's work [12] which is representative of relevant semiconductors, and in particular of $\mathrm{Si}$ ) and where the other symbols have their usual meaning. For series connected subcells, again with the positive photocurrent sign convention, the overall multijunction bias $V$ as a function of multijunction series current density $J$ is given by

$$
V(J)=\frac{K_{B} T}{q} \ln \left[\prod_{1}^{N}\left(\frac{J_{s c_{i}}-J}{J_{0 i}}+1\right)\right]
$$

thereby defining the $J(V)$ current-voltage characteristic. The maximum of the corresponding power-voltage characteristic yields the maximum possible efficiency achievable for any structure of $N$ ideal junctions. This is usually presented as a plot of efficiency as a function of bandgap showing isoefficiency contours that allows the potential of materials for high efficiency to be estimated at a glance. In Figure 1(a), we see the maximum efficiency achievable with two gaps, which is $42.2 \%$ in the conditions specified earlier for materials with bandgaps 0.96 and $1.64 \mathrm{eV}$.

Replacing the lower $0.96 \mathrm{eV}$ material with slightly higher bandgap silicon has a very slightly lower efficiency limit of $41.9 \%$ for bandgaps $1.12(\mathrm{Si})$ and $1.74 \mathrm{eV}$. The good match is underlined by the fact that the two solutions occupy two local neighbouring maxima on the isoefficiency contour. 

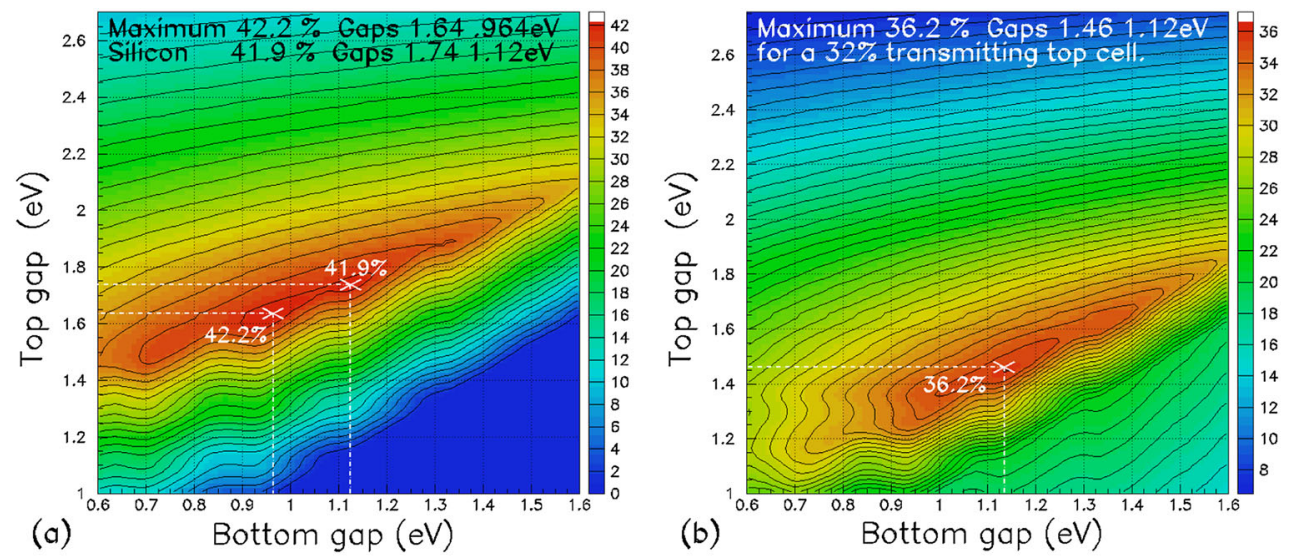

Figure 1. Tandem junction radiative efficiencies for an AM1.5G solar spectrum showing (a) the maximum dual junction efficiency of 42.2\% (bandgaps 1.64 and $0.964 \mathrm{eV}$ ) and the silicon-based tandem efficiency maximum at $41.9 \%$ (bandgaps 1.74 and $1.12 \mathrm{eV}$ ) and (b) maximum efficiency achievable with thinning the top cell (32\% optical transmission) for current matching with a Si $1.12 \mathrm{eV}$ bottom cell.

This bandgap restriction may be relaxed by considering subcells with less than unit EQE, specifically with optically thinned subcells in mind. While this reduces the limiting efficiency achievable because of increased thermalisation, it may be useful in order to mitigate material constraints. Figure 1(b) shows the efficiency obtainable in the radiative limit by thinning the top cell such that the ideal bottom cell gap approaches $\mathrm{Si}$. Having achieved this, the top cell ideal bandgap is one with $68 \%$ overall absorptivity, consequently transmitting $32 \%$ of the spectrum to the bottom $\mathrm{Si}$. The optimum top cell bandgap of $1.46 \mathrm{eV}$ in this case being fortuitously close to $\mathrm{GaAs}$ at $1.42 \mathrm{eV}$ is an accidental bonus as we shall see subsequently.

Figure 2(a) shows similar evaluations of Si for triple junction cells, where the ideal limit has a middle junction ideal bandgap of $1.21 \mathrm{eV}$ for an efficiency of $47.2 \%$. Figure 2(b) shows the efficiency profile for the maximum achievable with a silicon middle bandgap cell. We see that a slightly lower efficiency limit of $45.4 \%$ is achievable with a silicon middle gap cell. Although the loss is greater than for the tandem case, this retains the record-breaking potential.

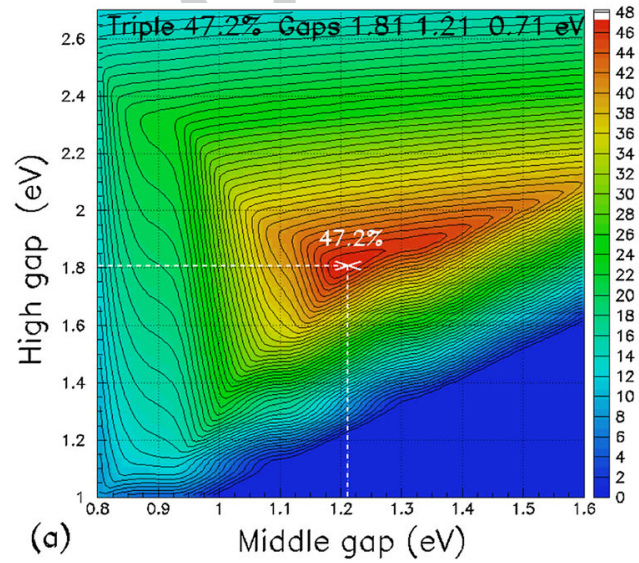

These introductory remarks set out the suitability of silicon for multijunction cells in the ideal limit. In the following sections, we go on to describe a realistic, quantitative model of triple junction cells in order to design multiple junction cells on silicon substrates.

\section{QUANTITATIVE MULTIJUNCTION MODEL}

In order to design test structures for the novel growth method, we use an analytical model SOL that has been Q6 reported in more detail elsewhere [13], but of which we sketch the main aspects here firstly for a single junction. With material parameters for the majority of semiconductors in the III-V family, drawn from the literature, including $\mathrm{Si}(\mathrm{Ge})$, the model evaluates the $\mathrm{EQE}$ and photocurrent $J_{P H}$ as a function of bias by standard analytical solutions [12] of transport and continuity equations in the depletion approximation for one-dimensional structures with abrupt

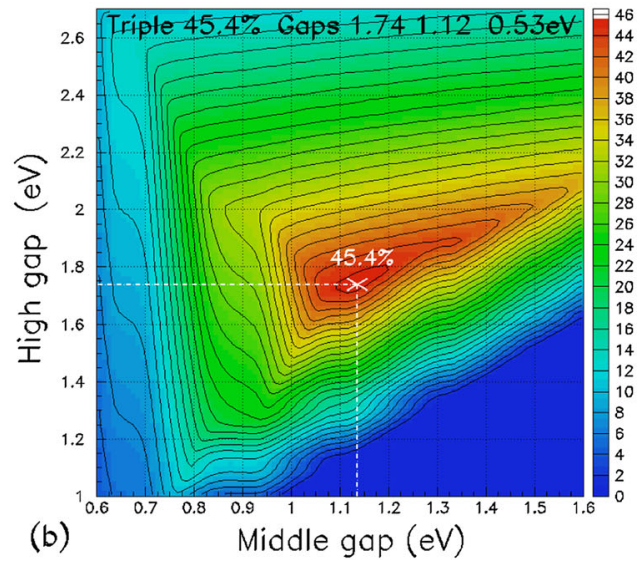

Figure 2. Triple junction solar cell radiative limit efficiencies for an AM1.5G solar spectrum as a function of top and middle bandgap subcells for a single lower bandgap cell in each case, showing (a) the absolute maximum of $47.2 \%$ (bandgaps $1.81,1.21$ and $0.71 \mathrm{eV}$ ) and (b) the maximum of $45.4 \%$ occurring for a silicon middle gap cell (bandgaps $1.74,1.12$ and $0.53 \mathrm{eV}$ ). 
interfaces. The point of interest in this model is the detailed accounting of loss mechanisms by explicit solution of the nonradiative and radiative recombination losses in the different regions of the cell, and the inclusion of series and shunt resistances for each subcell. As such, the radiative and nonradiative recombination currents in the chargeneutral layers are described by the Shockley diffusion or injection current [14] as follows:

$$
J_{S}(V)=q\left(e^{\frac{q V}{K^{T}}}-1\right)\left[\begin{array}{c}
\frac{n_{i p}^{2}}{N_{A}} \frac{D_{n}}{L_{n}}\left(\frac{\frac{S_{n} L_{n}}{D_{n}} \cosh \frac{x_{p}}{L_{n}}+\sinh \frac{x_{p}}{L_{n}}}{\frac{S_{n} L_{n}}{D_{n}} \cosh \frac{x_{p}}{L_{n}}+\sinh \frac{x_{p}}{L_{n}}}\right) \\
+\frac{n_{i n}^{2}}{N_{D}} \frac{D_{p}}{L_{p}}\left(\frac{\frac{S_{p} L_{p}}{D_{p}} \cosh \frac{x_{n}}{L_{p}}+\sinh \frac{x_{n}}{L_{p}}}{\frac{S_{p} L_{p}}{D_{p}} \cosh \frac{x_{n}}{L_{p}}+\sinh \frac{x_{n}}{L_{p}}}\right)
\end{array}\right]
$$

where $n_{i p}$ is the intrinsic carrier concentration in the p-layer doped at a level $N_{A}$, of surface recombination velocity $S_{n}$, and corresponding parameters $n_{i n}$ and $N_{D}$ in the n-doped layer with its recombination velocity $S_{p}$.

The nonradiative recombination currents in the spacecharge region are described by the Shockley-Read-Hall (SRH) recombination current [15] with the standard expression

$$
J_{S R H}(V)=q \int_{x_{1}}^{x_{2}}\left(\frac{p(x) n(x)-n_{i}^{2}}{\tau_{n}\left(p(x)+p_{t}\right)+\tau_{p}\left(n(x)+n_{t}\right)}\right) d x
$$

where $x_{1}$ and $x_{2}$ are the edges of the space-charge region, $n$ $(x)$ and $p(x)$ are the electron and hole concentration as a function of position, $n_{t}$ and $p_{t}$ are the electron and hole trap occupation densities for mid-gap trap levels and $\tau_{n}$ and $\tau_{p}$ are the electron and hole nonradiative lifetimes, respectively.

The radiative recombination currents in space-charge layers are evaluated from the absorption coefficients and quasi-Fermi level separation in each region of the cell as

$$
J_{R A D}(V)=q \int_{0}^{\infty}\left(\frac{2 n^{2}}{h^{3} c^{2}}\left(\frac{E^{2}}{e(E-q \Delta \phi) / K_{b} T}\right) \int_{S} \alpha(E, \theta, S) d S\right) d E
$$

where $n$ is the refractive index of the material, $\Delta \phi$ is the quasi-Fermi level separation, and the other symbols have their usual meanings. The absorptivity $\alpha(E, \theta, s)$ is the line integral over position through the different layers of the cell along the optical path of radiation at angle $\theta$ with the normal exiting or entering surface $S$, the total emitting surface in three dimensions [16].

The sum of these three recombination currents therefore describes the radiative and nonradiative recombination dark currents in the cell. Following this analytical method, a little more analysis can evaluate the radiative efficiency of the structures [13].
A noteworthy feature of this approach combining the modelling of the radiative and nonradiative currents together with the EQE is that all the parameters determining these currents except for the SRH lifetimes are determined by the EQE, thereby minimising the number of free parameters. The combination of dark current and EQE fitting therefore leaves, as only free parameters, the SRH lifetimes. In the absence of better knowledge, and consistently with current continuity, the electron and hole nonradiative $\mathrm{SRH}$ lifetimes are assumed equal in practice, resulting in a single free parameter: the SRH lifetime.

The efficiency of the cell is then evaluated from the light current $J_{L}$ assuming superposition of dark current and photocurrent $J_{P H}$ as

$$
J_{L}(v)=J_{P H}-\left(J_{S}+J_{S R H}+J_{R A D}\right)
$$

by finding the maximum power point on the light current curve.

The corresponding multijunction structure requires series connection of subcells via tunnel junctions. At this design stage of the MULTISOLSI project, we rely on published values as a guideline and on numerical calculations for Si tunnel junctions we have performed with SILVACO software. These show that in GaAs tunnel junctions [17], for example, peak tunnelling currents above $10^{4} \mathrm{~A} / \mathrm{m}^{2}$ are readily obtainable. The total current density obtainable with the global AM1.5G terrestrial spectrum is $726 \mathrm{~A} / \mathrm{m}^{2}$. The multijunction current flow is therefore at least an order of magnitude less than that of a suitable GaAs tunnel junction, which therefore serves to cause a small voltage loss, as it is designed to. As such, in this work, we treat the tunnel junctions as absorbing layers from an optical point of view and as series resistance elements from the electrical point of view. In addition, we note that the losses incurred because of the tunnel junctions are of the order of $0.1 \%$ absolute due to a combination of optical and electrical penalties.

The multijunction current-voltage characteristic is therefore evaluated by separately calculating the currentvoltage characteristics of the subcells optically and electrically connected in series, including parallel and series resistance losses and numerically evaluating the resulting multijunction solar cell current. This approach has shown itself capable of quantitatively reproducing world record $\mathrm{EQE}$, dark current and light current characteristics of tandem and triple junction cells published by Japan Energy Corp. [18] and Spectrolab [19] (Tables I and II). While T1 T2 complete details including fits of EQE, dark and light current-voltage characteristics are available elsewhere [13], here we show the good fit to the EQE of the triple junction cell (Figure 3(a)). As described in detail in Ref. [13], the F3 modelling in both cases relies on minority carrier transport as a function of doping given in the literature.

It is important to note that the experimental $\mathrm{EQE}$ of this Spectrolab triple junction record cell is close to $100 \%$. This in part is due to the very low reflectivity achievable with multilayer antireflection (AR) coats, such as the double-layer 
Table I. Experimental data and SOL modelling of a record tandem solar cell [18] under an AM1.5G spectrum.

\begin{tabular}{lcccc}
\hline & $J_{S C}\left(\mathrm{~A} / \mathrm{m}^{2}\right)$ & $V_{O C}(\mathrm{~V})$ & $F F(\%)$ & Efficiency (\%) \\
\hline Japan Energy Corp. & 142.5 & 2.49 & 85.6 & 30.3 \\
Model SOL & 139.5 & 2.32 & 87.0 & 29.4 \\
\hline
\end{tabular}

Table II. Experimental data and SOL modelling of a Spectrolab triple junction record cell [19] under an AM1.5G spectrum.

\begin{tabular}{lccccc}
\hline & $J_{S C}\left(\mathrm{~A} / \mathrm{m}^{2}\right)$ & $V_{O C}(\mathrm{~V})$ & $V_{m p}(\mathrm{~V})$ & $F F(\%)$ & Efficiency (\%) \\
\hline Spectrolab & 143.7 & 2.62 & 2.30 & 85 & 32.0 \\
Model SOL & 143.2 & 2.62 & 2.31 & 86.0 & 32.4 \\
\hline
\end{tabular}

AR coat used by the modelling here. The high EQE is also due to the relaxation of minority carrier transport constraints in multijunction cells, which is a consequence of each subcell in the stack needing to absorb a shorter range of incident wavelengths close to the band-edge. In particular, the impact of front surface recombination is reduced.

The corresponding single-parameter dark current fitting is shown in Figure 3(b). It is worth underlining that this dark current fit uses the transport parameters validated by the EQE fitting as we have discussed, with the single SRH lifetime in the space-charge region the only fitting parameter for the dark current fit. The strength of this approach is illustrated by the close dark current fit, shown in Figure 3(b), to available data for the triple junction subcells, in terms of the radiative and nonradiative recombination mechanisms.

This combined validation of transport by fitting EQE and dark current gives confidence in the transport parameters used and confirms that the very high EQE predicted is to some degree over-optimistic only in the analytical calculation of the double-layer AR coat reflectivity. We cannot avoid this slight overestimation, however, without arbitrarily reducing cell transport efficiency below published values, or by including external parasitic losses that are present in real AR coats, such as absorption losses due to impurities or backscattering losses due to surface roughness for example. This point is further confirmed by comparison with the EQEs achieved in practice by Spectrolab that also nearly reach $100 \%$, as shown in Figure 3(a).

The principal transport parameters of the EQE and dark current fits are summarised in Table III for the Japan Energy Corp. tandem and Spectrolab triple cell fits. The quoted diffusion lengths in both cases are obtained from the literature as stated earlier for each emitter and base regions in each of the subcells in both cases. The diffusion lengths in all cases are of the order of microns, with the exception of $\mathrm{Ge}$ that benefits from significantly longer diffusion lengths as experimental studies in the literature have shown.

Also indicated in Table III are surface recombination velocities. The impact of these on the EQE cannot be easily decoupled from the diffusion lengths without a numerical fitting parameter exploiting the different wavelength dependence of recombination velocities and diffusion lengths. Here, we use a manual method and, using a fixed diffusion length determined by the material composition and doping, we vary the front and back recombination lengths to fit the short wavelength and long wavelength response, respectively. Following this procedure, these transport parameters are fixed by the EQE fit and determine the Shockley injection and surface recombination dark current mechanisms.

The EQE calculation therefore fixes the transport parameters. As a result, the only fitting parameter for the dark current calculation is the SRH lifetime in the spacecharge region, given in Table III. The values in all cases, including the much longer SRH lifetime for the Ge subcell, are determined from the available high bias data available from the Spectrolab publication [19]. The trends observed as a function of material, and in particular the long SRH
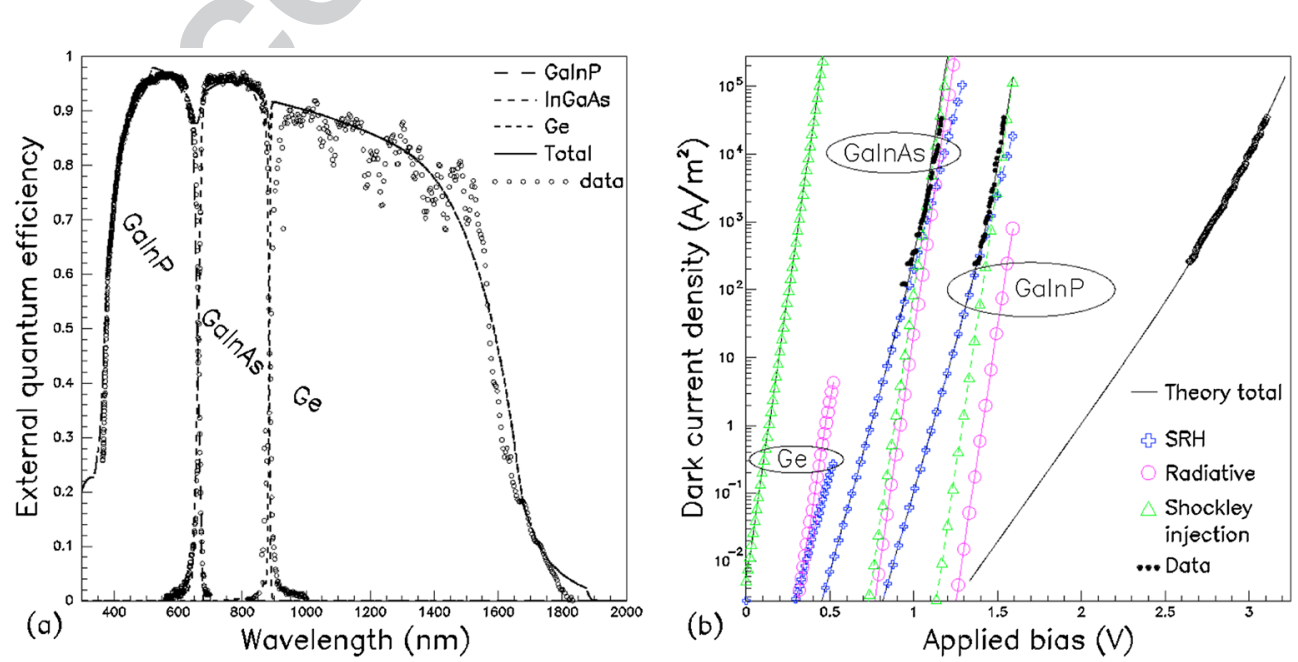

Figure 3. Record triple junction [19] showing (a) external quantum efficiency data and modelling with calculated reflectivity and (b) dark current modelling in terms of radiative and nonradiative contributions together with available data. 
Table III. Transport parameters: p-doped layer electron diffusion length diffusion lengths $L_{n}$ and n-doped layer hole diffusion length $L_{p}$, electron and hole recombination velocities $S_{n}$ and $S_{p}$ determine the EQE.

\begin{tabular}{llrrr}
\hline Tandem and triple cell transport parameters & $L_{n}(\mu \mathrm{m})$ & $S_{n}(\mathrm{~m} / \mathrm{s})$ & $L_{p}(\mu \mathrm{m})$ & $S_{p}(\mathrm{~m} / \mathrm{s})$ \\
\hline JEC tandem-GalnP & 0.4 & 750 & 2 & 50 \\
JEC tandem-GaAs & 1.124 & 20 & 7.6 & 1 \\
Spectrolab triple-GalnP & 5.11 & 100 & 1.56 & 35 \\
Spectrolab triple-GalnAs & 0.28 & 3000 & 1 & 20 \\
Spectrolab triple-Ge & 62.3 & 140 & 499 & 5 \\
\hline
\end{tabular}

The dark current is determined by the same transport parameters plus $\tau_{S R H}$ the Shockley-Read-Hall (SRH) lifetime that is the single free parameter. EQE, external quantum efficiency; JEC, Japan Energy Corp.

lifetime we see for $\mathrm{Ge}$, are confirmed by a brief review of net SRH lifetimes in the literature. Somewhat fortuitously, the data available, while not supplying separate IV data for the Ge subcell, provide data for the middle and top bandgap subcells, in a bias range that allows us to fit the total triple junction dark current, and therefore the $\mathrm{Ge}$ subcell dark current, with a high degree of confidence that results from the exact simultaneous fit obtained for middle GaInAs subcell, top GaInP subcell and the combined triple dark currents seen in Figure 3(b).

Summarising this modelling, Tables I and II show the main cell performance figures of merit under AM1.5G in the cases of both the Japan Energy Corp. tandem record [18] and the Spectrolab triple junction record [19], showing good agreement with, in the worst case $a \approx 3 \%$, relative underestimation of efficiency by SOL in the case of the tandem cell.

In the following sections, we will use this modelling approach to look at multijunction designs combining III-V materials on silicon. We will assume that material quality equal to that shown in these record cells is achievable using the low defect density III-V on silicon growth methods we have mentioned $[9,10]$.

\section{MULTIJUNCTION STRUCTURES ON SILICON}

We have identified ideal bandgaps for tandem and triple junction cells based on silicon and described a quantitative model. We use this to now describe the prototypes for fabrication by the novel growth method being developed within MULTISOLSI.

Because at present only binary III-V crystalline growth without propagation of bulk defects has been demonstrated, we first restrict the discussion to binary compounds for tandem structures, before discussing the extension to ternary compounds for tandem and triple junction solar cells.

\subsection{Binary tandem}

The first structure we propose is a GaAs on $\mathrm{Si}$ structure with a dual layer $\mathrm{MgF}_{2} / \mathrm{ZnS} \mathrm{AR}$ coat. We again note that the AR coat is idealised in the sense that it represents in all cases the best possible case with no parasitic losses, such as through absorption in the AR coat layers.
The tandem limiting efficiency calculations (Figure 1) show that the optimal top cell bandgap is $1.74 \mathrm{eV}$ for a Si lower gap cell, which is much greater than the $1.42 \mathrm{eV}$ bandgap of GaAs. This translates as a significant current mismatch with the GaAs cell current limited by the Si low gap cell.

As mentioned in our discussion of ideal radiative limits, this may be much improved, however, by adjusting the current balance between the two cells by adjusting the AR coat on the real cell and by adjusting the layer thicknesses in consequence. We found that the limiting efficiency of just $20.4 \%$ for an opaque GaAs cell on Si could be enormously increased to slightly more than $36 \%$ by thinning the top cell such that it absorbs only $68 \%$ of the incident photons with energies above its bandgap. While significantly lower than the limiting efficiency of $42.2 \%$ (Figure 1(a)), this is nonetheless an impressive target for a tandem solar cell and a suitable test bed for the growth methods being developed within the MULTISOLSI project.

For our binary semiconductor tandem design, we therefore adopt the strategy of thinning a GaAs cell in order to address this issue. The structure optimisation consists of jointly optimising the AR coat optimum wavelength and the GaAs cell thickness.

The substrate optimisation is independent and simpler, consisting solely of the standard optimisation of its EQE in terms of the trade-off between minority carrier collection efficiency versus total absorptivity for this layer. This optimisation proposes a $\mathrm{Si}$ substrate for this structure of $140 \mu \mathrm{m}$ total thickness with a shallow highly doped p-layer in contact with the GaAs tunnel junction.

The resulting structure is shown in Table IV. This first proposed test for the novel low defect density growth method [1] yields the EQE shown in Figure 4. The efficiency achieved in AM1.5G and therefore without concentration is $29 \%$ (Table V), which compares favourably with the long-standing $30 \%$ record result achieved by Takamoto et al. of the Japan Energy Corp. [18] in 1997 for the GaInP/ GaAs tandem cell under an AM1.5G terrestrial spectrum that we discussed in the modelling section.

\subsection{Ternary tandem}

Lattice-matched $\mathrm{Ga}_{0.51} \mathrm{InP}$ is a natural choice for a multijunction cell as it can be grown on a binary GaAs layer and because compatible windows of essentially lattice-matched 
Table IV. GaAs on Si substrate tandem structure with a suitable joint optimisation of GaAs layer thickness and dual layer AR coat design.

$\mathrm{MgF}_{2}(110 \mathrm{~nm}) / \mathrm{ZnS}(65.2 \mathrm{~nm})$ coat optimised at $800 \mathrm{~nm}$

\begin{tabular}{llcl}
\hline Layer & Material & $\begin{array}{c}\text { Thickness } \\
(\mu \mathrm{m})\end{array}$ & \multicolumn{1}{c}{ Doping $\left(\mathrm{m}^{-3}\right)$} \\
\hline Window & AlGaAs & 0.02 & p-type $\mathrm{C}>10^{25}$ \\
Base & GaAs & 0.15 & p-type $\mathrm{C}=2 \times 10^{24}$ \\
Emitter & GaAs & 0.2 & n-type $\mathrm{Si}=2 \times 10^{23}$ \\
Tunnel & GaAs & 0.01 & n-type $\mathrm{Si}$ degenerate \\
Tunnel & GaAs & 0.01 & -type $\mathrm{C}$ degenerate \\
Emitter & $\mathrm{Si}$ & 5 & p-type $\mathrm{B}=10^{24}$ \\
Base & $\mathrm{Si}$ & 140 & n-type $\mathrm{P}=10^{21}$ \\
BSF & $\mathrm{Si}$ & 1 & n-type $\mathrm{P}=10^{23}$ \\
\hline
\end{tabular}

$A R$, antireflection.

AlGaAs or preferably AlInP exist. However, its bandgap of $1.87 \mathrm{eV}$, being significantly higher than the ideal $1.74 \mathrm{eV}$, leads to this subcell being severely current limiting. The highest efficiency achievable is therefore just $30.16 \%$, which is barely better than the GaAs tandem.

Considering the GaInP top cells without the advantages of lattice matching to GaAs, the use of lower P compositions do enable current matching. While this in principle leads to efficiencies reaching over $32 \%$ for $\mathrm{Ga}_{0.34} \mathrm{InP}$, the absence of suitable lattice-matched window materials makes this an impractical choice.

The only suitable ternary remaining is GaAsP. This benefits from a lattice-matched AlInP window layer for a range

F5 of compositions [20]. Figure 5(a) shows the EQE of a GaAsP-based triple junction cell with an optimum AR coat of minimum reflectivity $700 \mathrm{~nm}$, which yields a good current match as illustrated by the light IV shown in Figure 5(b).
Table V. GaAs-Si tandem cell performance under an AM1.5G spectrum.

\begin{tabular}{lccccc}
\hline$J_{S C}\left(\mathrm{~A} / \mathrm{m}^{2}\right)$ & $\begin{array}{c}V_{O C} \\
(\mathrm{~V})\end{array}$ & $\begin{array}{c}V_{M P} \\
(\mathrm{~V})\end{array}$ & $\begin{array}{c}P_{\text {Max }} \\
\left(\mathrm{W} / \mathrm{m}^{2}\right)\end{array}$ & $\begin{array}{c}F F \\
(\%)\end{array}$ & $\begin{array}{c}\text { Efficiency } \\
(\%)\end{array}$ \\
\hline 200.4 & 1.67 & 1.50 & 292 & 87 & 29.2 \\
\hline
\end{tabular}

This structure is closer to the ideal limit in that no compromise of optically thinning the top cell is needed. The optimisation of bandgap and AR coat delivers a composition of $\mathrm{GaAsP}_{0.22}$ with a bandgap of $1.68 \mathrm{eV}$. As expected, this is close to a radiative limit value of $1.74 \mathrm{eV}$. The not insignificant difference is due to the visibly nonideal response of $\mathrm{GaAsP}_{0.22}$ near the band-edge, which is due mainly to the nonideal minority carrier transport in this material. This results in optimal emitter and base layer thicknesses being less than perfectly opaque and therefore in the $\mathrm{GaAsP}_{0.22}$ top cell slightly underproducing photocurrent. As a result, the quantitative optimisation procedure yields a slightly lower bandgap than the ideal.

The reduction in corresponding efficiency is due to the nonideality of the material primarily from the remaining partial transparency near the band-edge and from the departure of the recombination mechanisms from the radiative limit. We note in passing that evaluation of the dark current contributions (not shown for brevity) shows that the overall structure is dominated by Shockley injection currents at the maximum power point.

The consequence of the improved design flexibility is that improved current matching shown in Table VI. We see that this structure exceeds $32 \%$ efficiency, with higher $J_{S C}, V_{O C}$ and $3 \%$ absolute increase in efficiency with respect to the thinned $\mathrm{GaAs}$ tandem.
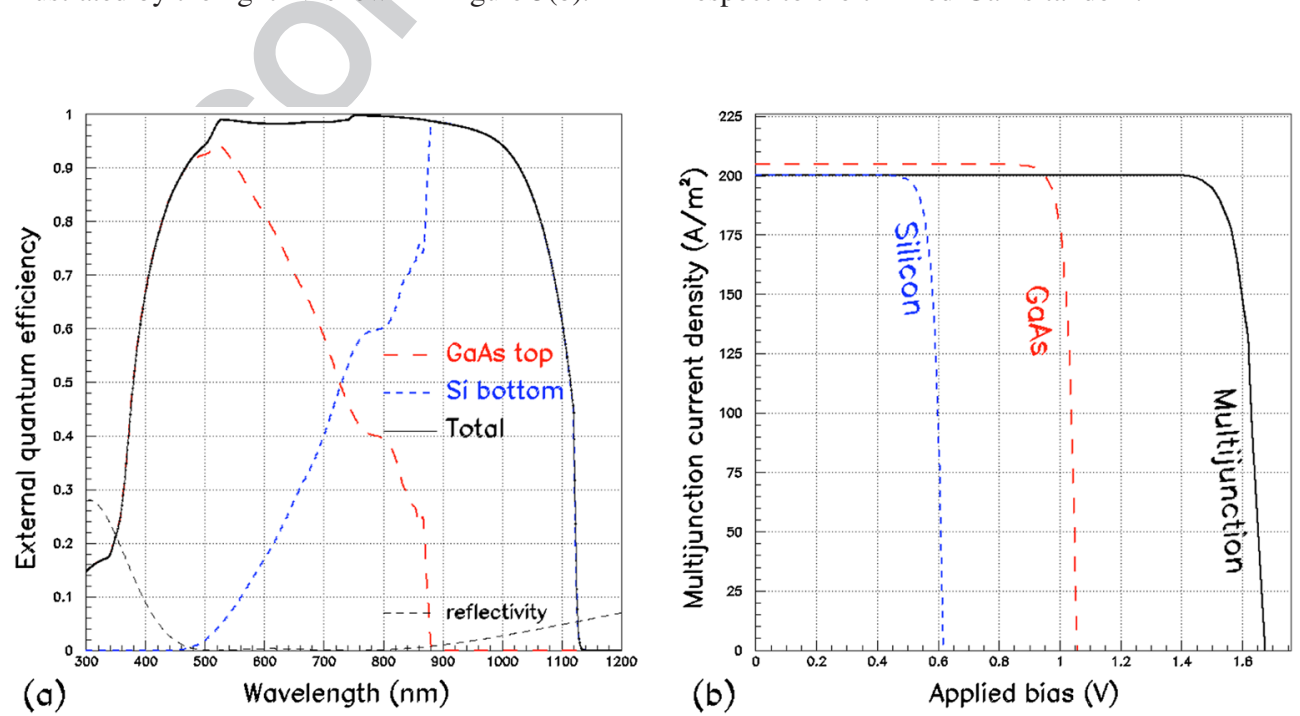

\begin{tabular}{l} 
T6 \\
Q11 \\
\hline
\end{tabular}

Figure 4. (a) Modelled external quantum efficiency of the silicon-based tandem structure with a cross optimised antireflection coat and GaAs high gap subcell thickness to ensure current continuity. (b) The modelled light current characteristics show the close current matching achieved and the lack of significant series resistance associated with the tunnel junction. 

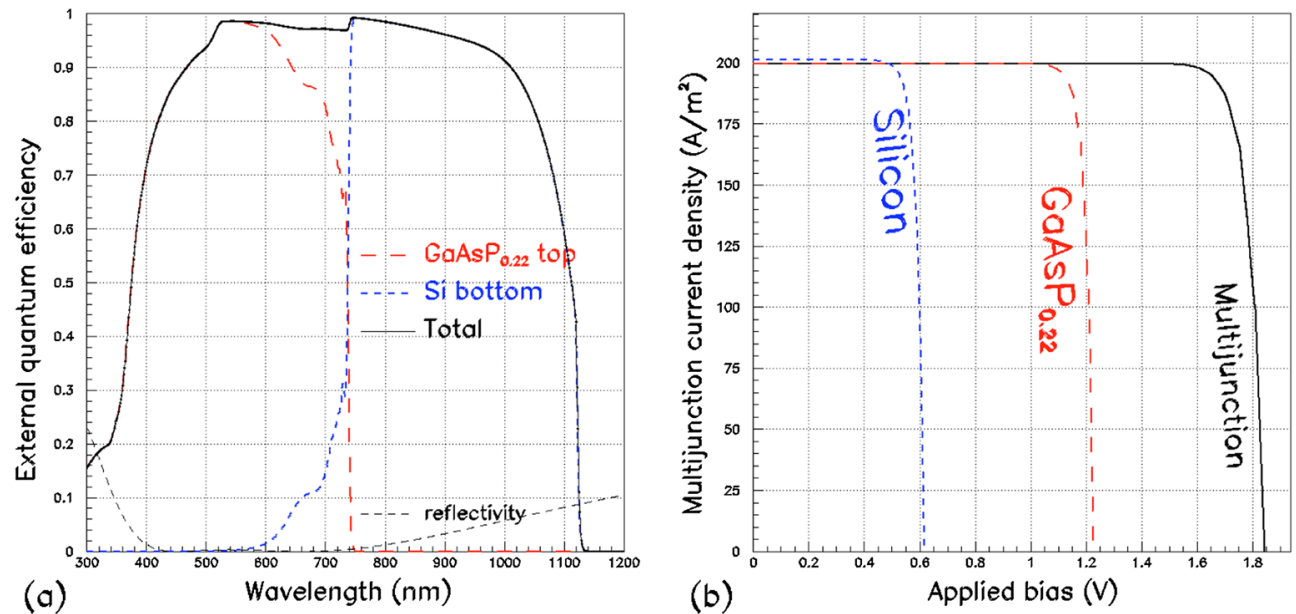

Figure 5. Ternary GaAsP $\mathrm{P}_{0.22} / \mathrm{Si}$ tandem response modelling. (a) The external quantum efficiency (EQE) shows a less than ideal top cell EQE near the band-edge resulting in an optimum top cell gap $(1.68 \mathrm{eV})$ slightly lower than the ideal limit $(1.74 \mathrm{eV})$ that nevertheless results (b) in close current matching and an efficiency of over $32 \%$.

Table VI. GaAsP/Si tandem cell performance under an AM1.5G spectrum.

\begin{tabular}{lccccc}
\hline$J_{S C}\left(\mathrm{~A} / \mathrm{m}^{2}\right)$ & $\begin{array}{c}V_{O C} \\
(\mathrm{~V})\end{array}$ & $\begin{array}{c}V_{M P} \\
(\mathrm{~V})\end{array}$ & $\begin{array}{c}P_{\text {Max }} \\
\left(\mathrm{W} / \mathrm{m}^{2}\right)\end{array}$ & $\begin{array}{c}F F \\
(\%)\end{array}$ & $\begin{array}{c}\text { Efficiency } \\
(\%)\end{array}$ \\
\hline 199.7 & 1.84 & 1.65 & 322 & 88 & 32.2 \\
\hline
\end{tabular}

\subsection{Triple junction structures}

The extension of the tandem to triple junction devices is obvious but requires epitaxy on both sides of the Si substrate that thereby takes on the role of middle junction solar cell. The low bandgap materials available include Ge. This material is, however, ill suited of the growth methods we are considering because of the necessity of growing a $\mathrm{Ge}$
Table VII. Triple junction thinned GaAs/ Si/ GalnAs cell modelled performance under an AM1.5G spectrum.

\begin{tabular}{lccccc}
\hline$J_{S C}\left(\mathrm{~A} / \mathrm{m}^{2}\right)$ & $\begin{array}{c}V_{O C} \\
(\mathrm{~V})\end{array}$ & $\begin{array}{c}V_{M P} \\
(\mathrm{~V})\end{array}$ & $\begin{array}{c}P_{\text {Max }} \\
\left(\mathrm{W} / \mathrm{m}^{2}\right)\end{array}$ & $\begin{array}{c}F F \\
(\%)\end{array}$ & $\begin{array}{c}\text { Efficiency } \\
(\%)\end{array}$ \\
\hline 198.8 & 1.95 & 1.69 & 329 & 85 & 32.9 \\
\hline
\end{tabular}

subcell of hundreds of microns in thickness, due to its low absorption coefficient. This leaves us with GaInAs as the only available low bandgap material. We will not consider the nitride alloys here because of challenging materials issues that remain unresolved [5].

In the following sections, we will therefore rely on a GaInAs bottom cell. A longer treatment would entail fully optimising top and bottom subcell structures. In this case,
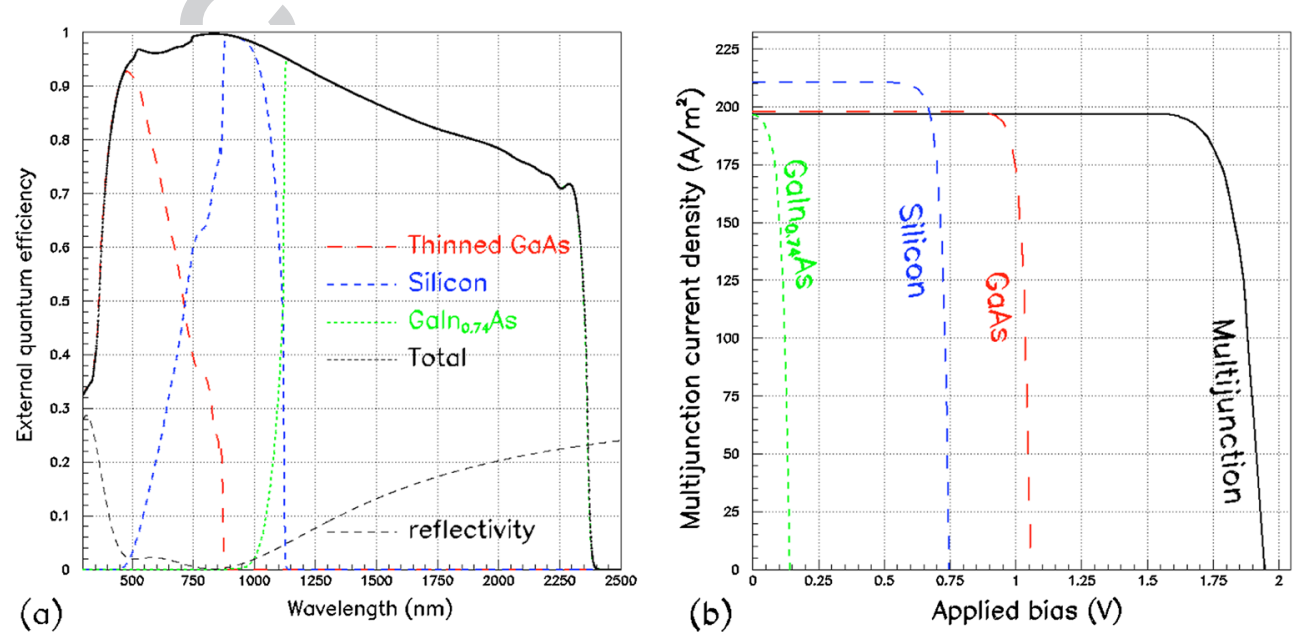

Figure 6. Thinned GaAs-Si-GalnAs triple junction structure modelled performance with joint optimisation of GalnAs composition, GaAs thickness and antireflection coat, reaching $32.9 \%$. 

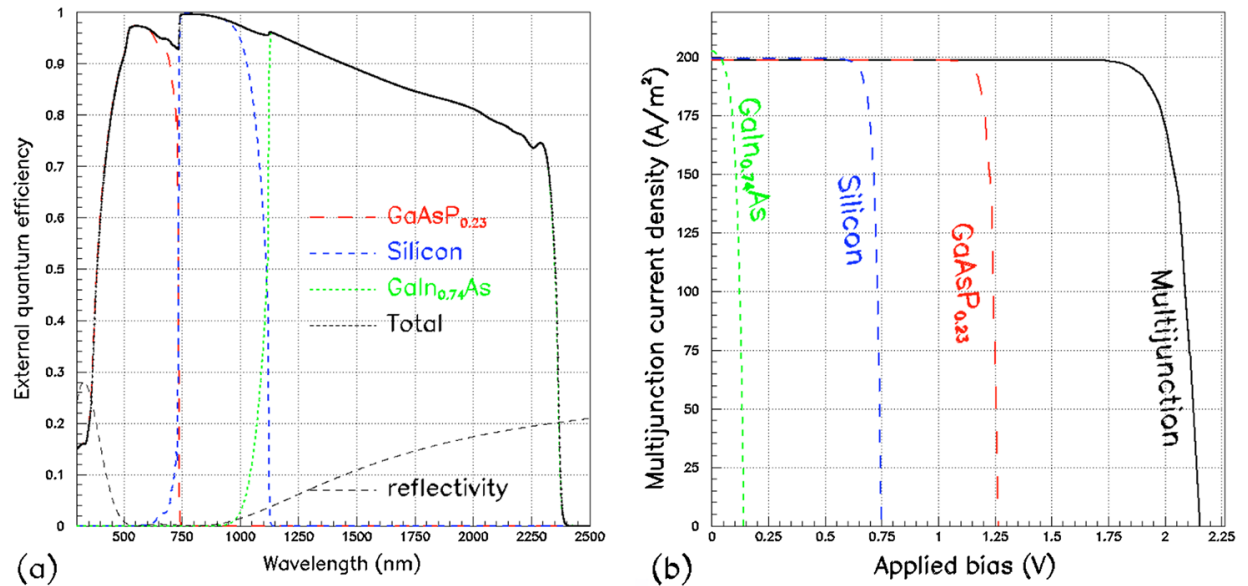

(b)

Applied bias (V)

Figure 7. Modelled performance of the triple cell with GaAsP top cell reaching $36.5 \%$.

Table VIII. Modelled performance of the triple junction $\mathrm{GaAsP}_{0.23} / \mathrm{Si} / \mathrm{Galn}_{0.74} \mathrm{As}$ cell performance under an AM1.5G spectrum.

\begin{tabular}{lccccc}
\hline$J_{S C}\left(\mathrm{~A} / \mathrm{m}^{2}\right)$ & $\begin{array}{c}V_{O C} \\
(\mathrm{~V})\end{array}$ & $\begin{array}{c}V_{M P} \\
(\mathrm{~V})\end{array}$ & $\begin{array}{c}P_{\text {Max }} \\
\left(\mathrm{W} / \mathrm{m}^{2}\right)\end{array}$ & $\begin{array}{c}F F \\
(\%)\end{array}$ & $\begin{array}{c}\text { Efficiency } \\
(\%)\end{array}$ \\
\hline 199.0 & 2.15 & 1.90 & 365 & 85 & 36.5 \\
\hline
\end{tabular}

for illustrative purposes, we only consider a GaInAs structure with a bandgap corresponding to the ideal limit for a Si-based triple junction (Figure 2(b)). The bottom gap subcell structure in all cases is therefore a $\mathrm{Ga}_{0.74} \mathrm{InAs}$ $p-i-n$ structure of total thickness $6 \mu \mathrm{m}$, having the ideal bandgap of $0.53 \mathrm{eV}$ for the Si-based triple junction design. The thickness of this cell is a little excessive but is chosen as such in order to make the GaInAs cell essentially opaque, in line with the design philosophy of this work. In a practical device at the production stage, however, light trapping techniques ranging from back-surface reflectors to front surface texturing would be required to allow us to achieve similar performance with GaInAs layers of lower thickness. We therefore present modelling of this bottom subcell with binary and ternary top cells as before.

\subsection{Thinned GaAs triple junction}

F6 Figure 6(a) shows the EQE of a triple junction cell with a thinned GaAs binary top cell for current matching. The structure is obtained by varying only the GaAs cell thickness and the AR coat optimal wavelength, while leaving the $\mathrm{Si}$ and GaInAs subcells optimal. In keeping with the optimisation of the GaInAs structure for the triple cell ideal limit (Figure 2(b)), we find that the optimum GaAs thickness is unchanged from the tandem case. The AR coat optimisation, however, shifts to a slightly longer wavelength of $860 \mathrm{~nm}$.

We find (Figure 6(b)) that the Si cell overproduces current slightly and is forced into forwards bias, beyond its maximum power point. The optimisation process referred to previously shows that this configuration is preferable to that in which the GaAs and $\mathrm{Si}$ subcells are current matched by adjusting the AR coat and the GaAs thickness, and are both forced past their maximum power points by the current limiting GaInAs bottom gap cell.

The AM1.5G efficiency achieved in this case is $32.9 \%$, as shown in Table VII.

\subsection{Ternary triple junction}

For the ternary case, we consider only GaAsP, as having suitable window materials as discussed earlier. In this case, as before, no compromise is necessary given the variable gap of the top subcell. An optimisation of AR coat and of top cell bandgap yields a $\mathrm{GaAsP}_{0.23}$ top cell with a bandgap of $1.69 \mathrm{eV}$, which is very slightly higher than the tandem case and which remains significantly lower than the ideal $1.74 \mathrm{eV}$.

As in the tandem case, the slightly lower bandgap than expected is consistent with the less than ideal EQE of the GaAsP cell (Figure 7(a)) and in particular because of the significant short wavelength losses entailed recombination at the interface with the AlInP window. The light current modelling (Figure 7(b)), however, shows exact current matching achieved by the optimisation process in this case.

As a result of this more flexible and better optimised structure, the efficiency achieved (Table VIII) is significantly higher, reaching $36.5 \%$ in AM1.5G. This represents $80 \%$ of the radiative efficiency limit for a triple junction cell.

\section{CONCLUSIONS}

Investigating the use of $\mathrm{Si}$ for multijunction cells, we have looked at optimal yet nonideal designs in the ideal radiative limit that are constrained by the inclusion of a $\mathrm{Si}$ subcell. These designs show that high efficiencies are 
achievable by balancing competing compromises of material restrictions and nonideal optical properties.

In order to design real cells, we have developed a quantitative analytical model. We have validated this model by quantitatively reproducing state-of-the-art light and dark current characteristics of record tandem and triple junction solar cells. The strength of the model lies in the minimisation of free parameters via consistent modelling of EQE and dark current characteristics.

This leads to dark current fitting in terms of a single free parameter, which is the SRH nonradiative lifetime in the space-charge region. With the exception of the reflectivity calculations that assume loss-free dual layer $\mathrm{MgF} / \mathrm{ZnS}$ AR coats, the approach to modelling has been to use published experimental values for transport parameters, in order to maximise agreement with experimental data. The quantitative modelling of the record tandem and triple junction solar cells, together with the compatibility of transport parameters used with values in the literature, gives a high degree of confidence in this analytical modelling methodology. The minority carrier properties and SRH lifetimes used in the modelling are therefore reliable benchmarks for the material to be grown on Si by the growth methods developed within the MULTISOLSI project.

Applying this quantitative model to realistic solar cell designs combining Si and III-V materials, we first find that an appropriate tandem design of thinned GaAs on $\mathrm{Si}$ can deliver an efficiency of $29 \%$, close to the $30 \%$ world record achieved with a GaAs substrate under a terrestrial spectrum with no concentration.

Furthermore, we find that a more challenging growth of ternary materials delivers tandem efficiencies greater than $32 \%$ and triple junction efficiencies greater than $36 \%$.

These high efficiencies are remarkable in that they are achieved without solar concentration. They nevertheless reach efficiencies just a few per cent below the maximum efficiencies achieved to date, at concentrations of 500 suns and above. This lack of concentrating optics invites the clear advantage of simple photovoltaic systems. More importantly, from the cell design point of view, it significantly relaxes the design criteria for tunnel junctions between subcells, due to the significantly reduced and less demanding current flow achievable with a terrestrial global spectrum.

This work has been carried out within the MULTISOLSI project, which has demonstrated the growth of GaAs on $\mathrm{Si}$ without the formation of antiphase domains, and without the generation of bulk defects. Work continues to develop a finer theoretical understanding of the three-dimensional nature of the structures involved, of the corresponding tunnel junctions, and to optimise the growth and processing techniques required to fabricate these potentially groundbreaking designs.

\section{ACKNOWLEDGEMENTS}

The MULTISOLSI project is funded by the French Agence Nationale pour la Recherche under the programme ANR PROGELEC 2011 (ref. ANR-11-PRGE-0009).

\section{REFERENCES}

1. H Cotal, C Fetzer, J Boisvert, G Kinsey, R King, P Hebert, H Yoon, N Karam. III-V multijunction solar cells for concentrating photovoltaics. Energy and Environmental Science 2009; 2; 174-192. DOI: 10.1039/B809257E

2. Green MA, Cho E-C, Cho Y, Huang Y, Pink E, Trupke T, Lin A, Fangsuwannarak T, Puzzer T, Conibeer G, Corkish R. All-silicon tandem cells based on 'artificial' semiconductor synthesised using silicon quantum dots in a dielectric matrix. Proc. 20th European Photovoltaic Solar Energy Conf.(Barcelona, Spain). 2005.

3. M-j Yang, T Soga, T Jimbo, M Umeno. High efficiency monolithic GaAs/Si tandem solar cells grown by MOCVD. First WCPEC; Hawaii, Dec. 5-9, 1994; 1847-1850. DOI: 10.1109/WCPEC.1994.520725

4. Taguchi H, Okada N, Soga T, Jimbo T, Umeno M. GaAs/Si tandem solar cell using epitaxial lift-off technique. 3rd World Conference on Photovoltaic Energy Conversion May 11-18, 2003 Osaka. Japan.

5. Geisz JF, Olson JM, Friedman DJ. Toward a monolithic lattice-matched III-V on silicon tandem solar cell. 19th European PV Solar Energy Conference and Exhibit Paris, France June 7-11, 2004.

6. Geisz JF, Olson JM, Romero MJ, Jiang CS, Norman AG. Lattice-mismatched GaAsP solar cells grown on silicon by OMVPE. 4th World Conference on Photovoltaic Energy Conversion, 2006, Hawaii DOI: 10.1109/WCPEC.2006.279570

7. Lueck MR, Andre CL, Pitera AJ, Lee ML, Fitzgerald EA, Ringel SA. Dual junction GaInP/GaAs solar cells grown on metamorphic $\mathrm{SiGe} / \mathrm{Si}$ substrates with high open circuit voltage. IEEE Electron Device Letters 2006; 27(3). DOI: 10.1109/LED.2006.870250

8. Putyato MA, Semyagin BR, Emel'yanov EA, Pakhanov NA, Preobrazhenskii VV. Molecular-beam epitaxy of $\mathrm{GaAs} / \mathrm{Si}(001)$ structures for high-performance tandem AIIIBV/Si-solar energy converters on an active silicon substrate. Russian Physics Journal 2011; 53(9). DOI: 10.1007/s11182-011-9509-3

9. http://www.agence-nationale-recherche.fr/suivi-bilan/ energie-durable/production-renouvelable-et-gestion-de1-electricite/fiche-projet-progelec-2011/?tx_lwmsuivibilan_ pi2\%5BCODE\%5D=ANR-11-PRGE-0009

10. Renard C, Vincent L, Bouchier RD, Cherkashin N, Michel A, Claverie A, Connolly JP. Growth route toward III-V multispectral solar cells on silicon. Proc. 28th EU PVSEC, Paris, 2013.

11. Renard C, Cherkashin N, Jaffre A, Vincent L, Michel A, Molière T, Hamouche R, Yam V, Alvarez J, Fossard F, Mencaraglia D, Bouchier D. Dislocation and antiphase domain free microscale GaAs crystals 
grown on $\mathrm{SiO} 2$ from (001) Si nano-areas. Applied Physics Letters 2013; 102: 191915. DOI: 10.1063/ 1.4807386

12. Henry $\mathrm{CH}$. Limiting efficiencies of single and multiple energy gap terrestrial solar cells. Journal of Applied Physics 1980; 51(8): 4494. DOI: 10.1063/1.328272

13. Connolly JP, Mencaraglia D. III-V solar cells. chapter 5 in "Materials Challenges: Inorganic Photovoltaic Solar Energy", The Royal Society of Chemistry, Irvine S, Bagnall D (eds). In press, publication November 2013 (41 pages). Preprint: arXiv:1301.1278

14. Shockley W. Electrons and Holes in Semiconductors, Van Nostrand D (eds). Princeton, N.J., 1950.

15. Shockley W, Read WT. Physics Review 1952; 87: 835, and R.N.Hall, Phys. Rev. 87, 387. (1952).

16. Nelson J, Barnes J, Ekins-Daukes N, Kluftinger B, Tsui E, Barnham K. Observation of suppressed radiative recombination in single quantum well p-i-n photodiodes. Journal of Applied Physics 1997; 82: 6240. DOI: 10.1063/1.366510

17. Hermle M, Létay G, Philipps SP, Bett AW. Numerical simulation of tunnel diodes for multi-junction solar cells. Progress in Photovoltaics: Research and Applications 2008. DOI: 10.1002/pip

18. Takamoto T, Ikeda E, Kurita H, Ohmori M. Over $30 \%$ efficient InGaP/GaAs tandem solar cells. Applied Physics Letters 1997; 70(3). DOI: 10.1063/1.118419

19. King RR, Law DC, Edmondson KM, Fetzer CM, Sherif RA, Kinsey GS, Krut DD, Cotal HL, Karam NH. Metamorphic and lattice-matched solar cells under concentration. Proc. 4th WCPEC, Hawaii, 2006; 760. DOI: 10.1109/WCPEC.2006.279567

20. Gudovskikh AS, Kalyuzhnyy NA, Lantratov VM, Mintairov SA, Shvarts MZ, Andreev VM. Properties of interfaces in GaInP solar cells. Semiconductors 2009; 43(10): 1363-1368. DOI: 10.1134/S1063782609100194 


\section{Paper Presented at 28Th EU PVSEC, Paris, France, 2013}

\section{Designing III-V multijunction solar cells on silicon}

James P. Connolly, Denis Mencaraglia, Charles Renard and Daniel Bouchier

A novel growth technique for III-V growth on $\mathrm{Si}$ for photovoltaic applications allows the design of Q3 multijunction solar cells including an active Si substrate. This work analyses multijunction designs specifically for terrestrial applications using ideal limiting efficiency modelling and quantitative, realistic model. A range of available semiconductors is analysed, and realistic record-breaking designs are identified for tandem and triple junction cells in a terrestrial spectrum. 


\section{Author Query Form}

\section{Journal: Progress in Photovoltaics: Research and Applications}

\section{Article: pip_2463}

Dear Author,

During the copyediting of your paper, the following queries arose. Please respond to these by annotating your proofs with the necessary changes/additions.

- If you intend to annotate your proof electronically, please refer to the E-annotation guidelines.

- If you intend to annotate your proof by means of hard-copy mark-up, please refer to the proof mark-up symbols guidelines. If manually writing corrections on your proof and returning it by fax, do not write too close to the edge of the paper. Please remember that illegible mark-ups may delay publication.

Whether you opt for hard-copy or electronic annotation of your proofs, we recommend that you provide additional clarification of answers to queries by entering your answers on the query sheet, in addition to the text mark-up.

\begin{tabular}{|c|l|}
\hline Query No. & \multicolumn{1}{|c|}{ Query } \\
\hline Q1 & $\begin{array}{l}\text { AUTHOR: Please supply a short title that will be used as the running } \\
\text { head. }\end{array}$ \\
\hline Q2 & AUTHOR: Please check that authors and their affiliations are correct. \\
\hline Q3 & $\begin{array}{l}\text { AUTHOR: "A novel growth technique ..." Please check whether edit } \\
\text { made to this sentence is correct. }\end{array}$ \\
\hline Q4 & AUTHOR: Please define CMOS. \\
\hline Q5 & $\begin{array}{l}\text { AUTHOR: "The objective of this study being cheap terrestrial..." } \\
\text { Please check whether edit made t this sentence is correct. }\end{array}$ \\
\hline Q6 & AUTHOR: Please define SOL. \\
\hline Q8 & $\begin{array}{l}\text { AUTHOR: Please give address information for this SILVACO: town, } \\
\text { state (if applicable), and country. }\end{array}$ \\
\hline QUTHOR: To ensure consistency, the solidus system has been used for \\
combined units. Please check and confirm if this is correct.
\end{tabular}


Required software to e-Annotate PDFs: Adobe Acrobat Professional or Adobe Reader (version 7.0 or above). (Note that this document uses screenshots from Adobe Reader $\mathrm{X}$ )

The latest version of Acrobat Reader can be downloaded for free at: http://get.adobe.com/uk/reader/

Once you have Acrobat Reader open on your computer, click on the Comment tab at the right of the toolbar:

닙

This will open up a panel down the right side of the document. The majority of tools you will use for annotating your proof will be in the Annotations section, pictured opposite. We've picked out some of these tools below:

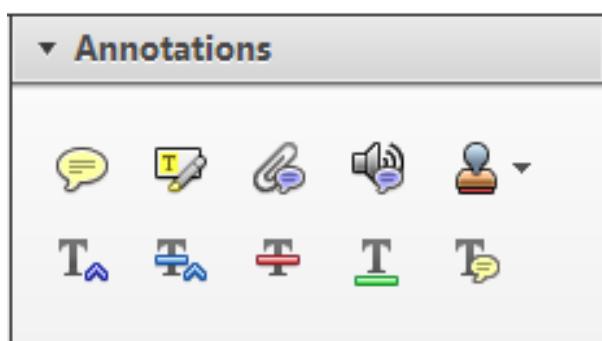

1. Replace (Ins) Tool - for replacing text.

Strikes a line through text and opens up a text box where replacement text can be entered.

How to use it

- Highlight a word or sentence.

- Click on the Replace (Ins) icon in the Annotations section.

- Type the replacement text into the blue box that appears.

Idard tramework for the analysis of $\mathrm{m}$ icy-Nevertheless, it also led to exog،

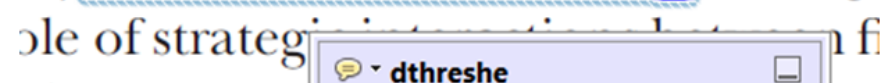
aber of comp 08/06/2011 15:58:17 is that the s1 nain compo: be level, are exc nc

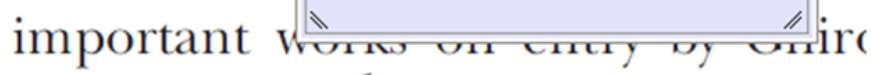
M heneferth) ${ }^{1}$ we anen the "hlarl $\mathrm{l}$

3. Add note to text Tool - for highlighting a section to be changed to bold or italic.

Th Highlights text in yellow and opens up a text box where comments can be entered.

How to use it

- Highlight the relevant section of text.

- Click on the Add note to text icon in the Annotations section.

- Type instruction on what should be changed regarding the text into the yellow box that appears.

namic responses of mark ups ent with the VAR evidence

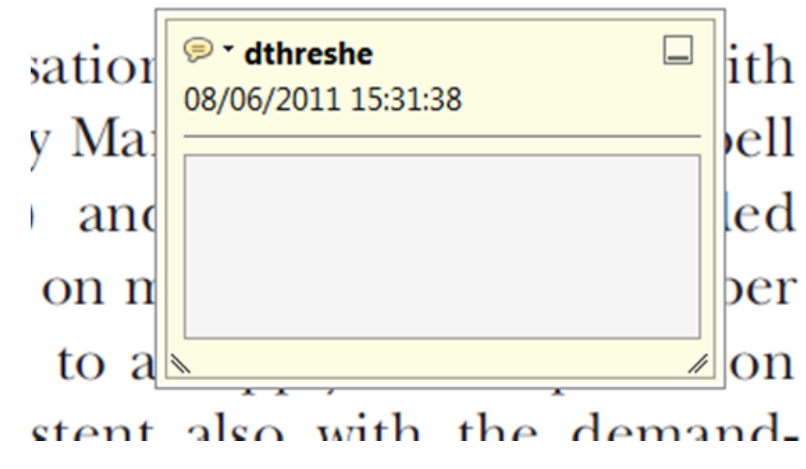

2. Strikethrough (Del) Tool - for deleting text.

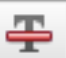

Strikes a red line through text that is to be deleted.

How to use it

- Highlight a word or sentence.

- Click on the Strikethrough (Del) icon in the Annotations section.

there is no room tor extra prohts al c ups are zero and the number of ret) values are not determined by Blanchard and Kiyotaki (1987), sfect competition in general equilil ts of aggregate demand and supply lassical framework assuming monol eph on evorenous number of firme

4. Add sticky note Tool - for making notes at specific points in the text.

Marks a point in the proof where a comment needs to be highlighted.

How to use it

- Click on the Add sticky note icon in the Annotations section.

- Click at the point in the proof where the comment should be inserted.

- Type the comment into the yellow box that appears.

lailu aliu suppiy silucks. hivsl ui

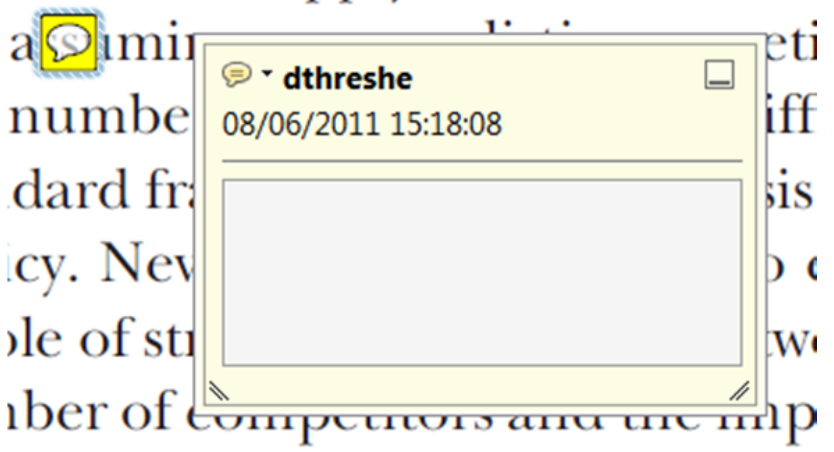

is that the structure of the sectc. 
5. Attach File Tool - for inserting large amounts of text or replacement figures.

Inserts an icon linking to the attached file in the appropriate pace in the text.

How to use it

- $\quad$ Click on the Attach File icon in the Annotations section.

- Click on the proof to where you'd like the attached file to be linked.

- Select the file to be attached from your computer or network.

- Select the colour and type of icon that will appear in the proof. Click OK.

E N D

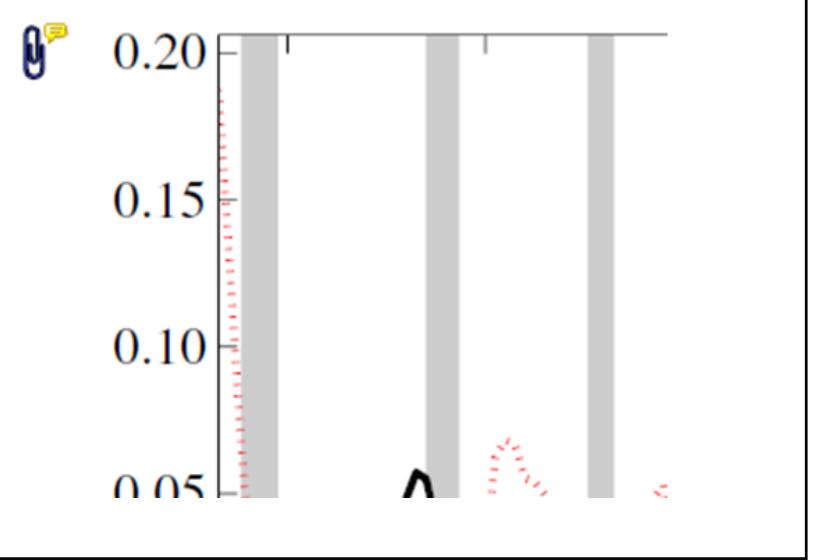

6. Add stamp Tool - for approving a proof if no corrections are required.

- Inserts a selected stamp onto an appropriate place in the proof.

\section{How to use it}

- $\quad$ Click on the Add stamp icon in the Annotations section.

- Select the stamp you want to use. (The Approved stamp is usually available directly in the menu that appears).

- Click on the proof where you'd like the stamp to appear. (Where a proof is to be approved as it is, this would normally be on the first page).

It the Dusiness cycie, starting with the on perfect competition, constant ret

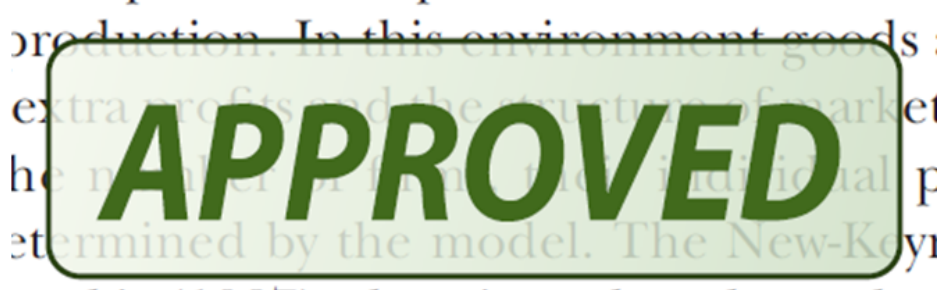
otaki (1987), has introduced produc general equilibrium models with nomin:

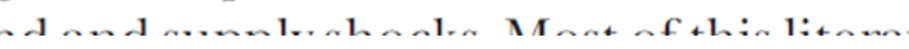

- Drawing Markups

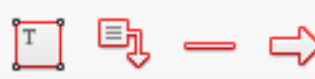

$0 \bigcirc \sqrt{6} \otimes$

\section{How to use it}

- Click on one of the shapes in the Drawing Markups section.

- Click on the proof at the relevant point and draw the selected shape with the cursor.

- To add a comment to the drawn shape, move the cursor over the shape until an arrowhead appears.

- Double click on the shape and type any text in the red box that appears.
7. Drawing Markups Tools - for drawing shapes, lines and freeform annotations on proofs and commenting on these marks.

Allows shapes, lines and freeform annotations to be drawn on proofs and for comment to be made on these marks.

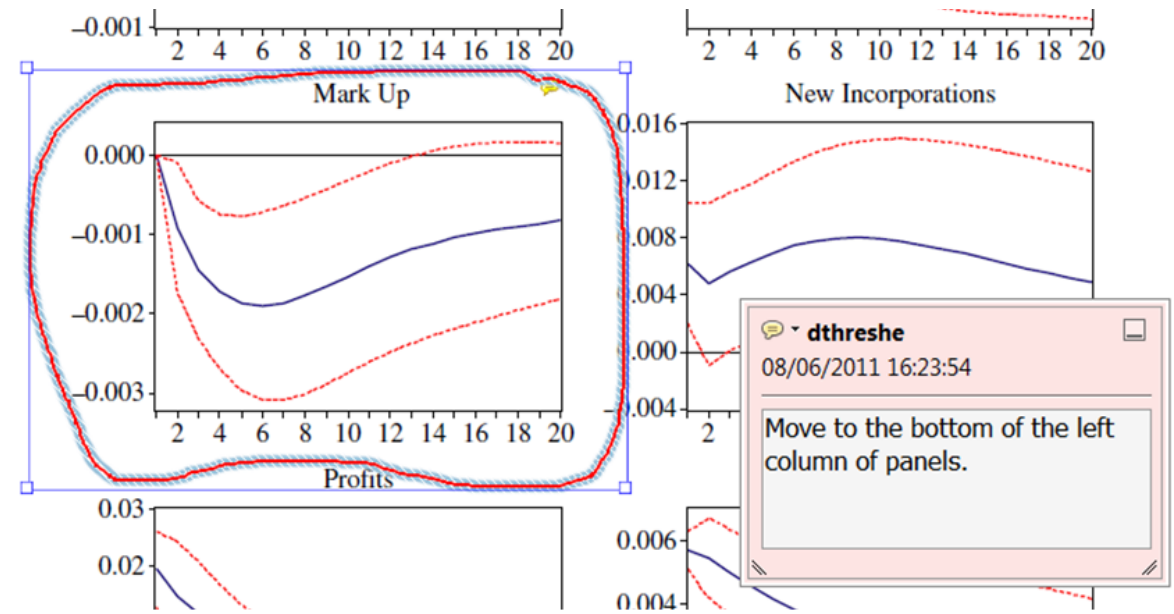

For further information on how to annotate proofs, click on the Help menu to reveal a list of further options:

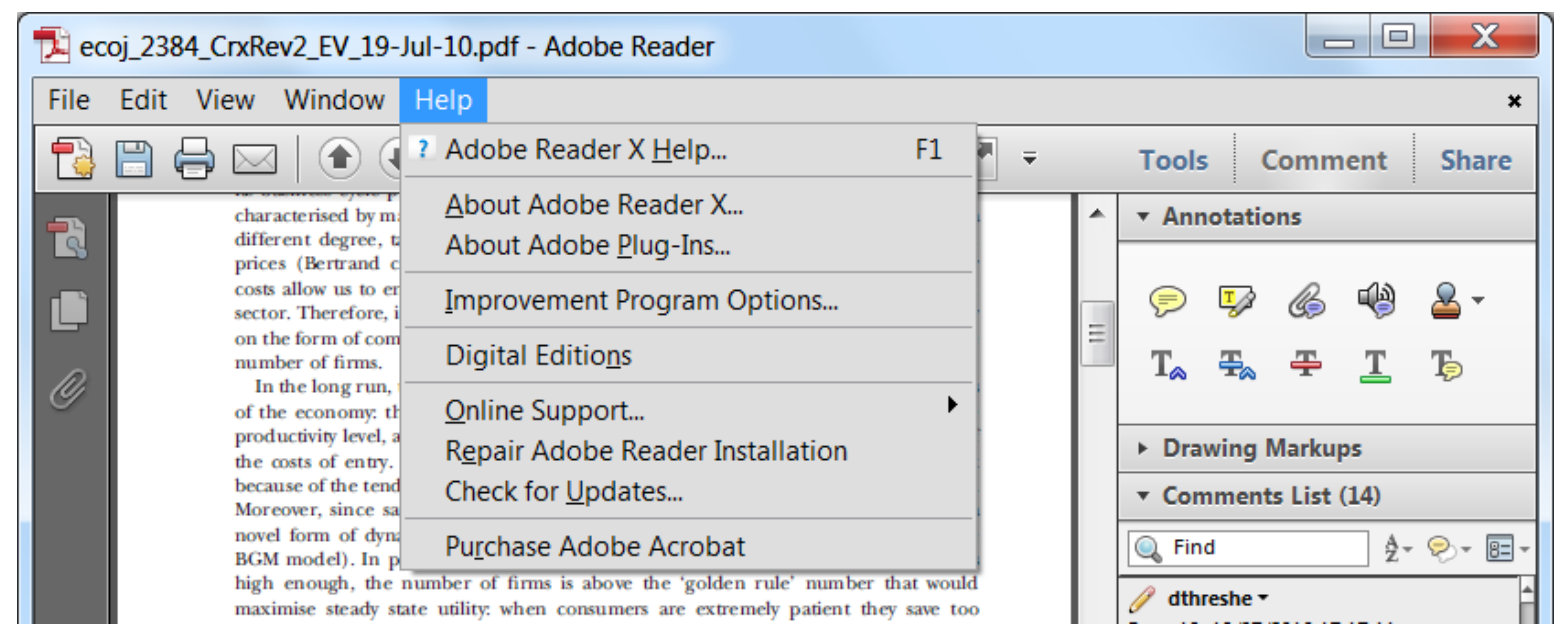

